 \\ Revista Vol. 24(47) \\ Prolegómenos enero-junio - ISSN: 0121-182x · e-ISSN: 1909-7727 - pp. 133-145
}

\title{
La armonización legislativa como instrumento de solución de conflictos en la Comunidad Andina*
}

\section{Carolina Blanco Alvarado ${ }^{a}$}

\begin{abstract}
Resumen: el objetivo del presente artículo es identificar la importancia de la armonización legislativa en la Comunidad Andina (CAN). Para el efecto, se considera que la referenciada armonización es un instrumento capaz de solucionar problemas de orden económico, social, político y jurídico, en el marco de las competencias compartidas entre la CAN y los países miembros. La metodología de investigación empleada fue de carácter cualitativo, ya que analiza, sin cálculos numéricos y atendiendo la dogmática teórica existente sobre el particular, el papel de la armonización legislativa en el marco de la CAN. Lo anterior desde el método de investigación descriptivo, ya que el manuscrito contextualiza desde el análisis documental, la temática de investigación planteada. Se concluye, entre otras cosas, que la armonización legislativa constituye instrumento jurídico capaz de simplificar el contexto normativo de los países miembros de la CAN.
\end{abstract}

Palabras clave: armonización legislativa; Comunidad Andina; derecho; unificación normativa

Recibido: 10 de febrero de 2021

Aceptado: 23 de febrero de 2021

Disponible en línea: 06 de agosto de 2021

Cómo citar: Blanco Alvarado, C. (2021). La armonización legislativa como instrumento de solución de conflictos en la Comunidad Andina. Prolegómenos, 24(47), 133-145. https://doi.org/10.18359/prole.5616

* Artículo de revisión. Producto del proyecto de investigación institucional "Derecho, Estado y Sociedad: Transformaciones del Derecho Público. Fase 2". Gestionado en la Facultad de Derecho de la Universidad Católica de Colombia.

a Doctora en Derecho, Universidad Santo Tomás, Bogotá, Colombia. Magíster en Derechos Fundamentales, Universidad Carlos III, Madrid, España. Especialista en Derecho Constitucional, Centro de Estudios Políticos y Constitucionales, Madrid, España. Especialista en Derecho Administrativo, Universidad del Rosario, Bogotá Colombia. Abogada de la Universidad Externado de Colombia. Docente e investigadora de la Universidad Católica, Bogotá, Colombia. Universidad Católica, Bogotá, Colombia.

Correo electrónico: rcblanco@ucatolica.edu.co ORCID: https://orcid.org/0000-0002-1354-4272 


\section{Legislative Harmonization as an Instrument for Conflict Resolution in the Andean Community}

Abstract: the objective of this article is to identify the importance of legislative harmonization in the Andean Community (CAN). For this purpose, it is considered that the referenced harmonization is an instrument capable of solving problems of an economic, social, political, and legal nature, within the framework of the shared competences between the CAN and the member countries. The research methodology used was qualitative, Since it analyzes the role of legislative harmonization within the framework of the CAN without numerical calculations, and taking into account the existing theoretical dogmatics on the matter. This is considered from the descriptive research method, since the manuscript contextualizes from the documentary analysis the research topic. It is concluded, among other things, that legislative harmonization constitutes a legal instrument capable of simplifying the regulatory context of the member countries of the CAN.

Keywords: legislative harmonization; Andean Community; law; normative unification

\section{A harmonização legislativa como instrumento de solução de conflitos na Comunidade Andina}

Resumo: o objetivo deste texto é identificar a importância da harmonização legislativa na Comunidade Andina (CAN). Para isso, é considerado que essa harmonização é um instrumento capaz de solucionar problemas de ordem econômica, social, política e jurídica, no âmbito das competências partilhadas entre a CAN e os países-membros. A metodologia de pesquisa utilizada foi de caráter qualitativo, já que analisa, sem cálculos numéricos e atendendo à dogmática teórica existente sobre o particular, o papel da harmonização legislativa no âmbito da CAN. O estudo se baseou no método de pesquisa descritivo, visto que o texto contextualiza, a partir da análise documental, a temática de pesquisa proposta.

Palavras-chave: harmonização legislativa; Comunidade Andina; direito; unificação normativa 


\section{Introducción}

Una de las acciones más importantes y seguramente una de las más complejas de consolidar, que debe realizarse dentro de cualquier proceso de integración (llámese este Unión Europea, Mercosur o Comunidad Andina-CAN), es la referente a la consolidación de armonizaciones legislativas. Dicha acción no solo es indispensable para lograr las finalidades del correspondiente proceso de integración, sino que su omisión por los Estados miembros del proceso integrador constituye, paralelamente, uno de los mayores retrocesos para el avance del proceso integracionista.

Sin lugar a equívocos, el ordenamiento jurídico colombiano no puede ser entendido como un sistema jurídico aislado y encerrado en sí mismo, sino que debe ser contextualizado con los ordenamientos nacionales de los restantes Estados miembros de la can. Para el efecto, dicha organización supone una realidad jurídica compleja, pues contiene múltiples niveles normativos, que van desde decisiones y resoluciones de orden comunitario, tratados y acuerdos internacionales, hasta normas constitucionales. Por ello, a pesar de la crisis que afronta, se considera que la CAN se vería favorecida por propuestas de integración jurídica, dentro de las que se encuentran las armonizaciones legislativas.

Para los países andinos, los efectos del fenómeno de la globalización suponen lograr aproximaciones en las legislaciones nacionales, con la finalidad de obtener sistemas jurídicos sistemáticos y coherentes; $y$, de esta manera, adecuarse de la mejor forma al fenómeno de la globalización. En este escenario, cobra importancia el instrumento de armonización legislativa, el cual requiere no solo del consentimiento de los Estados miembros, sino de la inclusión de temáticas que, definitivamente, no podrían ser objeto de armonización legislativa (cfr. Blanco-Alvarado, 2015a).

El Acuerdo de Cartagena (1969) determinó los objetivos de la CAN. Como actividades de interés para el proceso andino de integración, del acuerdo se deducen: el turismo, el transporte, el medioambiente, la educación y la salud. Para el efecto, la citada norma prevé:
Promover el desarrollo equilibrado y armónico de los países miembros en condiciones de equidad, mediante la integración y la cooperación económica y social; acelerar su crecimiento y la generación de ocupación; facilitar su participación en el proceso de integración regional, con miras a la formación gradual de un mercado común latinoamericano. (art. 1)

En concordancia con la citada norma, el Acuerdo de Cartagena prevé también que, de modo complementario a los mecanismos que utiliza para lograr los objetivos de la CAN, "se adelantarán, en forma concertada, programas y acciones de cooperación económica y social en el área del turismo; y acciones para el aprovechamiento y conservación de los recursos naturales, medio ambiente; y desarrollo social"2 (art. 3).

Las normas comunitarias a que alude, consagradas en el Derecho Comunitario Originario, han permitido que, en el marco del proceso de integración andino, se haya evidenciado una distribución de competencias compartidas entre los Estados miembros y la can. Para el efecto, entendemos por competencias compartidas aquellas gestionadas de manera concomitante por la CAN y los países miembros. En este sentido, tanto la CAN como los Estados andinos ostentan la facultad legal y constitucional para legislar y adoptar actos jurídicamente vinculantes sobre las referenciadas competencias. No obstante, de conformidad con Molina y Faíña (2005), es preciso aclarar que los Estados andinos pueden ejercer su competencia de legislar solamente en la medida en que la CAN no haya ejercido la suya, o si ha optado por no ejercerla ${ }^{3}$.

1 El Acuerdo de Cartagena evidencia la importancia de la integración económica en los países miembros y, la necesidad de lograr la integración jurídica para el citado efecto.

2 Al respecto, cfr. Blanco-Alvarado (2015b), donde se buscó justificar la importancia política, jurídica y social de la can en los Estados miembros, excluyendo la perspectiva económica.

3 Lo dispuesto es materialización de la característica de supranacionalidad del Derecho Comunitario Andino, esto es, la prevalencia de dicho sistema jurídico en contexto con los sistemas jurídicos nacionales de los Estados miembros. Al respecto, Cfr. Molina y Faíña (2005). 
En este orden de ideas, han sido competencias compartidas entre la CAN y los Estados andinos, temáticas relacionadas con medioambiente, turismo, transporte, salud y educación. En la actualidad, estas temáticas son objeto de regulación legal y comunitaria, de conformidad con el contenido del Acuerdo de Cartagena, sus protocolos y acuerdos reglamentarios y el Derecho Interno de tales Estados.

En este orden de ideas, se considera que temáticas referentes a medioambiente, turismo, transporte, salud y educación, podrían ser objeto de armonización legislativa en el marco de la cAN. Ello apoyaría en el procedimiento de solución a los conflictos económicos, políticos, jurídicos y sociales, de manera más eficiente y eficaz; y más contextualizada frente a los efectos de la globalización.

\section{La competencia de la CAN para consolidar propuestas de armonizaciones legislativa}

Atendiendo los mandatos constitucionales, de las Cartas Políticas de Bolivia, Colombia, Ecuador y Perú, los gobiernos de los citados Estados han gestionado y legalizado los tratados, acuerdos y protocolos que constituyen el Derecho Andino de la Integración u ordenamiento jurídico comunitario. Entre ellos se ubica: el Acuerdo de Cartagena (1973), el Tratado Constitutivo del Parlamento Andino (1984) y el Protocolo de Trujillo (1997) ${ }^{4}$.

De conformidad con el Acuerdo de Cartagena y sus actos jurídicos modificatorios, resulta procedente interrogarse sobre la competencia de la CAN para legalizar armonizaciones legislativas entre los Estados andinos. Esta cuestión es importante porque, para poder intervenir en la temática, la CAN debe tener competencia para abordarla, pues, en caso contrario, su actuación estaría viciada de legalidad. En aras de responder a la pregunta referenciada, es importante resaltar que la comunidad

4 Es importante resaltar que, a pesar de que la mayoría de los Estados miembros de la can justifican constitucionalmente el proceso de integración andino, en la actualidad se evidencian obstáculos de orden jurídico que no permiten avanzar en ese proceso. Cfr. Blanco-Alvarado (2014). supone un proceso político y jurídico de articulación de los niveles nacional y supranacional, en una serie de instituciones y organizaciones ubicadas dentro y fuera de los Estados miembros, quienes ostentan de autonomía y responsabilidad conjunta en el avance del proceso integrador ${ }^{5}$.

En este orden de ideas, el Acuerdo de Cartagena previó:

El presente acuerdo tiene por objetivos promover el desarrollo equilibrado y armónico de los países miembros, en condiciones de equidad, mediante la integración y la cooperación económica y social; acelerar su crecimiento y la generación de ocupación; facilitar su participación en el proceso de integración regional, con miras a la formación gradual de un mercado común latinoamericano ${ }^{6}$. (art. 1)

Atendiendo el contenido de la citada norma, la misión fundamental de la CAN es promover el desarrollo de los países miembros, mediante la realización de políticas o acciones comunes. Desde esa perspectiva, las armonizaciones legislativas en la CAN adquieren importancia. En este sentido, al Parlamento Andino, de conformidad con el Derecho Comunitario Andino, se ha asignado la competencia de generar proyectos de normas jurídicas andinas, mediante sugerencias a los órganos del Sistema Andino de Integración. Para el efecto, dichos proyectos de normas deben evidenciar temas de interés común, para su incorporación en el ordenamiento jurídico andino; en aras de promover y consolidar, armonizaciones de legislaciones en ciertas temáticas en los países miembros.

De conformidad con el artículo 12 del Tratado Constitutivo del Parlamento Andino ${ }^{7}$, se ha

5 Lo dispuesto supone replantear la noción clásica de soberanía; temática que resulta recontextualizada por la existencia de la can, como proceso integrador. Cfr. Blanco-Alvarado (2013).

6 El artículo primero del Acuerdo de Cartagena permite afirmar que la integración andina no es solo un proceso de integración de carácter económico, sino que también supone una integración jurídica, acompañada de la integración política y social.

7 El Tratado Constitutivo del Parlamento Andino fue suscrito el 25 de octubre de 1979, y por él se constituyó el Parlamento Andino, como órgano deliberante y democrático de la can. 
asignado competencias normativas a dicho órgano internacional, el cual constituye un Órgano Supranacional Andino, establecido como ente central en el Acuerdo de Cartagena de 1967. Ello se debe a que, de conformidad con el Tratado Constitutivo, el Parlamento Andino ostenta de la competencia de examinar el desarrollo del proceso de la integración andina y el cumplimiento de sus objetivos. En consecuencia, dicho órgano tiene la competencia de formular proyectos de armonización legislativa que vinculen a los países miembros, en temáticas no solamente referidas a aspectos de orden económico, sino también, políticos, sociales y jurídicos. Lo anterior con la finalidad de promover el desarrollo en los países andinos y fortalecer el proceso andino de integración (cfr. BlancoAlvarado, 2017).

\section{La naturaleza jurídica de la armonización legislativa en la CAN}

De conformidad con Viver (1996), "los estudios dedicados al procedimiento legislativo constituyen una parte importante de lo que tradicionalmente se denomina ciencia de la legislación”. Dichos estudios han evidenciado el objetivo de mejorar la calidad formal y material de las normas jurídicas. En este sentido, como propuesta para mejorar la calidad formal y material de las normas jurídicas, resulta pertinente reflexionar sobre la posibilidad de cierta homogeneidad normativa en los sistemas jurídicos de los países miembros de la CAN. Lo anterior, a fin de lograr que las disposiciones normativas sean eficaces, esto es, que sirvan a los objetivos para los que fueron dictadas $y$, a la vez, eficientes; es decir, que cumplan con sus objetivos con el menor costo posible ${ }^{8}$.

En concordancia con lo dispuesto en líneas anteriores, resulta importante referirnos a la noción técnica legislativa, la cual, desde el escenario lógico, ha sido asimilable a la gestión de la actividad

8 La doctrina ha corroborado la importancia de la eficacia normativa en el marco del Estado democrático. Al respecto, Cfr. Barragán-Ronderos (2016). legislativa o normativa. Sin embargo, es pertinente anotar que la doctrina jurídica ha evidenciado ausencia de univocidad de criterios frente a aquella noción y, para el efecto, la comunidad académica le ha ofrecido diferentes conceptos. En este orden de ideas, se ha considerado que la técnica legislativa supone un conocimiento direccionado hacia la composición y redacción de normas jurídicas, que requiere del apoyo de procedimientos y recursos de diversa índole (científicos, tecnológicos) y cuyo objeto es el estudio del lenguaje legal y la estructura interna de las disposiciones jurídicas.

Es importante resaltar que la actualidad exige que las disposiciones normativas, insertas en un sistema jurídico, aseguren calidad normativa, y coherencia global (cfr. Forero-Salcedo, 2014). Por ello, la técnica legislativa no solo debe propender por establecer reglas jurídicas desde el escenario formal, sino también reglas jurídicas cuyo contenido garantice la unidad del sistema jurídico. En este sentido, la técnica legislativa, desde el escenario de la CAN, debe generar reglas y principios que garanticen la integración coherente de los distintos ordenamientos jurídicos andinos y como consecuencia, de las diversas fuentes del derecho'.

Ha sido tendencia jurídica el intento de reducir la diversidad legal entre países. Lo anterior ha existido desde que los sujetos de derecho empezaron a desarrollar actividades comerciales entre sí, atravesando los tradicionales límites políticos ${ }^{10}$. En este sentido, resulta procedente aludir a la noción de armonización legislativa. Para el efecto, la noción de armonizar ha sido entendida como el instrumento tendiente a evitar el rechazo de dos o más partes de un todo, o dos o más ítems que deben concurrir al mismo fin. Así pues, se ha entendido que la armonización legislativa es el procedimiento que tiende a unificar el marco jurídico vigente de un país, conforme con el espíritu y el contenido de los instrumentos internacionales.

9 Lo dispuesto, no es que una de las formas de materializar la globalización del Derecho, temática desarrollada por Garzón-Buenaventura (2013).

10 En países del tercer mundo, la armonización legislativa es una forma de moldearse frente al fenómeno de la globalización jurídica. Cfr. Stephan (1999). 
Desde el escenario de la CAN, se ha considerado que la armonización legislativa es el procedimiento a través del cual disminuyen las situaciones de desigualdad jurídica o normativa entre los Estados andinos. Dicha armonización facilita la solución de conflictos jurídicos, de modo que constituye una herramienta básica para generar autonomía política, con visión de progreso para la población andina.

Es pertinente anotar que la noción de la armonización legislativa es un concepto que no ha merecido mayor controversia en la doctrina, ya que si bien no existe una completa uniformidad en la definición, tampoco existe fuerte controversia en cuanto a su contenido. Así, Lerner (2004) la define como "un proceso por el cual las barreras entre los sistemas jurídicos tienden a desaparecer y los sistemas jurídicos van incorporando normas comunes o similares" (p. 921). Dicho concepto supone el hacer compatibles las disposiciones de dos o más sistemas jurídicos.

A su turno, Goldring (1978) define a la armonización legislativa como "un proceso por medio del cual los efectos de una transacción, bajo un determinado ordenamiento, son llevados lo más cerca posible a los que se generarían por la misma transacción, bajo otro conjunto de disposiciones" (p. 289). Keily (2003), por su parte, agrega que la armonización legislativa alude a "acercar las disposiciones y hacerlas similares" (p. 14).

A estas conceptualizaciones se suman, por un lado, la de Gopalan (2003), quien la establece como "la producción de resultados armónicos, mediante la extracción de las mejores soluciones, en un área determinada, de los distintos ordenamientos" (p. 809). Por otro, la de Rodríguez (2009), quien sostiene que la armonización normativa se relaciona con "procedimientos que suponen una modificación de la legislación de varios Estados, sin alcanzar una completa unificación, pero con el propósito de crear un afinidad esencial entre varias legislaciones, ya sea de tipo sustantivo o de tipo adjetivo o procesal" (p. 229).

En consecuencia, en el marco de procesos de integración, la armonización normativa es un procedimiento legislativo que propende por disminuir las diferencias normativas entre distintos sistemas jurídicos. Lo anterior, con la finalidad de lograr mejores soluciones jurídicas, económicas, sociales y políticas. Ahora bien, dicho procedimiento legislativo permite evidenciar temáticas jurídicas afines, entre las diferentes regulaciones que las hagan compatibles. En este orden de ideas, conviene resaltar que los procedimientos de armonización legislativa son un intento en la búsqueda de disminuir la diversidad legal, en aras de instaurar temas comunes entre los diversos ordenamientos jurídicos, que permitan establecer una mayor compatibilidad entre ellos y, de esta manera, lograr soluciones a problemas de orden jurídico, político, económico y social, de manera eficiente y eficaz (cfr. Patarroyo y Benavides, 2014).

Sin duda, en el marco de las relaciones internacionales, resulta indispensable armonizar aspectos de orden económico, jurídico, social y político, a fin de que los países se contextualicen de mejor manera frente a la realidad internacional. Atendiendo al proceso andino de integración, se han evidenciado diferentes temáticas que podrían ser objeto de armonización normativa. Lo anterior permite promover el principio de seguridad jurídica, mandato fundamental en las relaciones jurídicas entre Estados; en las relaciones jurídicas entre Estado y particulares; y en las relaciones jurídicas entre particulares ${ }^{11}$.

Por ello, es importante anotar que la armonización legislativa en la CAN contribuye a crear un marco de seguridad jurídica que permitiría y facilitaría el desarrollo armónico y continuo de los países miembros. Ya que busca introducir sistemas modernos de relación para un espacio jurídico, social, económico y político más amplio, con el propósito de elevar el nivel de vida de la población; a la vez constituye un medio de liberación de la situación de dependencia en la que se encuentran los países en vía de desarrollo, cuyas estructuras

11 Las armonizaciones legislativas promueven y fortalecen el principio de seguridad jurídica. Al respecto, cfr. Veliev (2000). 
económicas han sido modeladas por las exigencias del comercio exterior de las grandes economías ${ }^{12}$.

\section{Unificación normativa y armonización legislativa}

A pesar de que, en ocasiones, es común encontrar dentro de la doctrina el uso indiferente de las nociones unificación normativa y armonización legislativa, lo cierto es que, si bien son términos relacionados, su razón de ser es diferente. Al respecto, es importante resaltar que, a diferencia de la unificación, la armonización normativa no solo tolera la existencia de diferencias entre los ordenamientos, sino que también permite divergencias en la aplicación del instrumento armonizador normativo (cfr. Rodríguez-Martínez, 2016).

Atendiendo la naturaleza jurídica del proceso andino de integración, la armonización normativa pretende eliminar las diferencias normativas entre diferentes sistemas jurídicos, que afecten el progreso económico, social, político y jurídico de los países miembros; pero ello no implica la completa eliminación de la diferencia. Este último caso supone otro procedimiento legislativo, que también resulta procedente en procesos de integración, denominado unificación normativa, el cual propende por la sustitución de normas de los Estados que participan en el proceso, eliminando las diferencias existentes y estableciendo un único cuerpo normativo común de carácter supranacional (Calonje y Palomares, 2015).

En el escenario de la armonización legislativa, es procedente afirmar diversos grados de implementación normativa. Para el efecto, de conformidad con Bonilla (2013) "esta posibilidad es producto de los grados de compatibilidad que pueden existir entre los sistemas, del éxito del instrumento armonizador y de las diferencias que fueron eliminadas en el proceso" (p. 92). La unificación

12 La consolidación de propuestas de armonización legislativa en países del tercer mundo les permite contextualizarse de mejor manera frente a la globalización jurídica. Sobre este particular, cfr. Cortés-Zambrano (2013). normativa, por el contrario, es de carácter absoluto e implica la completa sustitución de las normas de los Estados que participan en el procedimiento.

En consecuencia, cabe aclarar que la armonización normativa no evidencia como finalidad la eliminación de todas las diferencias entre los diversos sistemas jurídicos que participan en el proceso de integración. Por el contrario, busca eliminar las diferencias sustanciales que impiden el desarrollo de una gestión temática de interés de los países miembros. Por ello, la necesidad de consolidar una armonización legislativa frente a la temática en particular (Humbarita, 2015).

De conformidad con lo dicho, resulta procedente considerar que, en el marco de procesos de integración, lo ideal es la unificación normativa; y la herramienta para su materialización es la armonización. También cabe aclarar que, si bien la armonización y la unificación son conceptos interrelacionados, tanto que incluso llega a entenderse la armonización como objetivo de la unificación; en realidad, son conceptos diferenciables, con implicaciones y consecuencias distintas.

\section{La relación entre armonización normativa y el Derecho comparado}

La relación entre armonización normativa y Derecho comparado ha generado diversos criterios doctrinales. El debate al respecto se encuentra en si existe necesidad de utilizar el Derecho comparado para legalizar un proyecto de armonización legislativa. Sobre esto, se han desarrollado dos criterios: desde el escenario histórico, Sacco (1989) afirma que la armonización normativa no requiere del Derecho comparado; a diferencia de Zweigert (1988), quien opina que la armonización legislativa sí requiere del derecho comparado.

Se considera que no es posible adelantar un procedimiento de armonización legislativo exitoso sin haber llevado a cabo un estudio acucioso de Derecho comparado. Para el efecto, el análisis propio del Derecho comparado facilita el desarrollo de la correspondiente armonización legislativa. Es 
importante no olvidar que el Derecho comparado, primero, permite comprender las reglas e instituciones contenidas en los distintos sistemas jurídicos y, segundo, explica el desarrollo histórico y la realidad de las instituciones y disposiciones existentes en un ordenamiento jurídico ${ }^{13}$.

Debe resaltarse que la implementación de una norma jurídica, como el instrumento de armonización legislativa, en un sistema jurídico con respecto al cual no se ha efectuado un análisis del contexto político, social, económico y jurídico puede no ser exitosa. Este efecto negativo se hace evidente especialmente en casos de trasplantes legales, esto es, cuando una disposición normativa es extraída de un ordenamiento jurídico para ser insertada y aplicada en otro. Lo anterior acontece por la ambición del correspondiente órgano legislativo de obtener resultados a la mayor brevedad, omitiendo realizar un análisis del contexto político, económico, jurídico y social que existía al momento de la expedición de la normatividad; situación que genera resultados desastrosos ${ }^{14}$.

En consecuencia, el Derecho comparado es vital para corroborar los efectos positivos de la armonización legislativa, ya que permite, en principio, establecer qué debe, o no, ser objeto de armonización legislativa. De esta forma, el Derecho comparado colabora en el procedimiento de armonización legislativa y crea un marco metodológico para afrontar el trabajo comparativo y encontrar el más amplio común denominador entre los diferentes sistemas jurídicos a armonizar.

\section{justificación jurídica de armonizaciones legislativas en la CAN}

Si bien el nacimiento del Estado moderno supuso un gran avance en la garantía de protección del principio de seguridad jurídica; dicha situación no

13 Todo proceso de armonización legislativa supone como punto de partida un análisis de Derecho comparado, con la metodología y método propios de esta disciplina. Cfr. Quiroz-Villalobos (2014).

14 Detalles sobre este asunto, se encuentran en Rodríguez-Cely (2014). aconteció, ni está aconteciendo, en el contexto de las relaciones internacionales (Saidiza y Carvajal, 2016).

Los Estados andinos han monopolizado el proceso de creación de las leyes y como consecuencia de ello, el orden político, económico, social y jurídico en su propio ámbito territorial. A pesar de ello, interaccionan internacionalmente entre sí. En el marco de las relaciones internacionales, los Estados andinos funcionan monopolizando el procedimiento de creación de leyes y, como consecuencia, monopolizando el poder y la capacidad de coacción en su ámbito territorial, interactuando en un mundo cada vez más interdependiente.

Ello ha generado un modelo anacrónico e, incluso, terriblemente perjudicial para los países miembros de la CAN. Al respecto, de conformidad con Faíña y Novo (2005) y recurriendo a la clásica idea de Hobbes del desorden, esto es, de la guerra de todos contra todos, resulta procedente afirmar la ausencia de una autoridad coactiva en el ámbito internacional, lo cual genera rasgos hobbesianos en las relaciones entre Estados que en la actualidad por regla general funcionan de manera independiente.

La actualidad ha evidenciado un proceso de gran mutación social, consecuencia de la globalización, lo cual ha constituido un conjunto contradictorio de procesos jurídicos, políticos, sociales y económicos, que se materializan con la ideología propia del capitalismo neoliberal. De ese modo, resulta procedente anotar que no hay sector de la vida económica, política y social inmune a los efectos de la globalización y, para efectos de las presentes páginas, la vida jurídica no ha sido excepción.

Las decisiones adoptadas por organismos como el Banco Mundial, Banco Central Europeo y Reserva Federal Norteamericana repercuten, directa o indirectamente en el continente. En consecuencia, impactan en la vida económica, social, política y jurídica de los Estados en vías de desarrollo, como los Estados andinos. Por ello, para que los países andinos, en tanto Estados en vías de desarrollo, puedan contextualizarse frente a los efectos del fenómeno de la globalización es menester, entre otras propuestas, armonizar legislativamente políticas nacionales comunes. 
Como consecuencia de lo anterior, deben crearse órganos o instituciones que se encarguen de conducir el proceso integracionista andino y aplicar las medidas concretas que requiere, para promover la integración y lograr la compatibilización legislativa que dé fluidez y coherencia a los diferentes sistemas jurídicos que concurren en el proceso de integración. Para el efecto, es pertinente no olvidar que la armonización legislativa supone un proceso normativo de identificación de coincidencias normativas y de la superación de diferencias normativas, respetando siempre el particularismo de cada Estado miembro.

De conformidad con Blanco-Alvarado (2013b), "como consecuencia del fenómeno de la globalización, es de relevancia anotar la multiplicación de las instancias productoras de Derecho y el entramado de sus respectivos ámbitos de validez". Esto nos pone ante un panorama jurídico difuso y complejo, que exige a los Estados andinos interactuar desde los escenarios interno y externo, promoviendo la justicia, el principio de seguridad jurídica y el principio y derecho constitucional a la igualdad. Por lo anterior, las propuestas de armonización legislativa en la CAN permiten que los países andinos ostenten de ordenamientos jurídicos contextualizados con el fenómeno de la globalización.

Ahora bien, tampoco debemos obviar la constante erosión del imperio de la ley que está produciendo determinados tipos de globalización. Resulta, entonces, que no solo es que las normas estatales sean impotentes para enfrentarse a las acciones globales, sino que la actividad de las grandes corporaciones transnacionales ha ocasionado la deslocalización y desagregación de responsabilidades jurídicas, debido a la falta de transparencia y anonimato de sus actores. Dicha situación genera un ataque frontal al Estado de derecho y a la configuración de la autonomía política y jurídica de los Estados andinos, ya que decisiones que afectan a la población andina son tomadas, justamente, al margen de la rama legislativa de los países andinos (cfr. Guarín-Ramírez, 2013).

En un mundo globalizado es indispensable que los países en vías de desarrollo, como los Estados andinos, logren, desde el escario de la integración, normas neutrales. No son pocos los autores que confirman esta necesidad. McKendrick (2006) señala que una ley armonizada tiene la apariencia de neutralidad de la que carecen las regulaciones locales. Mientras que Rodríguez (2009) prevé cómo la armonización normativa pretende normas neutrales, es decir, normas que garanticen principios de cualquier ordenamiento. En consecuencia, no es ajeno a la doctrina el hecho de que el instrumento de armonización legislativa esté integrado por un conjunto de disposiciones con contenido neutral.

Se considera que, en el contexto de la CAN, las propuestas de armonización legislativa permiten promover la congruencia y coherencia normativa de los sistemas jurídicos de los Estados andinos. En consecuencia, se produciría el fortalecimiento del principio de seguridad jurídica y la garantía de principios y derechos constitucionales, como la igualdad, los cuales se han visto menoscabados con el fenómeno de la globalización (cfr. Gallego-Marín, 2014).

Es importante no olvidar que el surgimiento y perfeccionamiento de nuevos medios de transporte y el desarrollo de las tecnologías de la información han hecho menos complejas las relaciones comerciales entre sujetos de derecho en diferentes Estados. Bonilla (2013) considera que, si bien se ha evidenciado avance en el desarrollo de los medios de transporte y de la tecnología de la información, "la existencia de leyes divergentes entre los distintos Estados y la dificultad en la determinación de la ley aplicable a la relación en caso de conflicto constituyen obstáculos para el desarrollo del comercio internacional"; y aclara que la Asamblea General de la Organización de las Naciones Unidas (ONU) "mediante la Resolución 2205 del 17 diciembre de 1966, puso de presente cómo las diferencias entre los ordenamientos que regulan el comercio constituían uno de los mayores obstáculos para el desarrollo del comercio internacional" (p. 97).

Es por lo previsto que la armonización legislativa desde la CAN debe ser entendida como herramienta que promueve el comercio internacional dentro de la can y de los Estados miembros. Lo anterior se logra mediante la eliminación de barreras que generen diversidad legal. En este orden de ideas, de conformidad con Bar (2002), la 
consolidación de propuestas de armonización legislativa permite que

las partes contratantes no solo evidencien claridad de cuál es la regulación que los rige, sino que también estarán frente a una regulación que no es del todo desconocida y que, al ser obligatoria para ellas, no existirá la posibilidad de imponer un ordenamiento que favorezca a una determinada posición contractual. (p. 34; traducción propia)

Las propuestas de armonización legislativa en la CAN permiten reducir los costos de transacción por operaciones comerciales. Este es uno de los principales fundamentos que sustentan la necesidad de armonizar las leyes que regulan el comercio internacional. Para el efecto, es importante recordar que las propuestas de armonización legislativa están fundamentadas en la creencia de que la diversidad legal causa mayores costos de transacción, disminuye los beneficios económicos y desalienta la participación de los consumidores en las transacciones internacionales.

El aumento en los costos de transacciones, como consecuencia de la diversidad legal, son argumentados por Wagner (2007), quien prevé los motivos por los cuales las divergencias entre los sistemas legales los incrementan: (1) "Por la adquisición de información sobre la regulación que regirá la relación y la adaptación a esta”; y (2) “por la gran cantidad de disposiciones y procesos que aumentan la incertidumbre legal en las transacciones comerciales" (p. 12; traducción propia). A su turno, Roumeen y Reshef (2006) señalan: "Cuando se producen transacciones entre dos partes que tienen normas y cortes distintas, estas incurrirán en costos para conocer las instituciones de cada uno y para redactar un contrato compatible con estas regulaciones" (p. 4; traducción propia).

Es importante resaltar que estos costos de transacción, los cuales tienen deben ser cubiertos por las partes contratantes, afectan en particular a pequeños y medianos empresario; a diferencia de las grandes empresas, que utilizan su posición dominante en la negociación para imponer como ley aplicable al contrato una que sea de su conocimiento e implique mayores gastos. Sin embargo, es preciso aclarar, que no solo las pequeñas y medianas empresas resultan afectadas por los referenciados costos de transacción, ya que las grandes empresas, para superar la diversidad legal y sus consecuencias en el mercado, constituyen sucursales extranjeras encargadas de los negocios que se tienen en el lugar en que se requiera ejecutar un contrato. La creación de este vehículo legal implica un aumento de los costos que, si bien no impide la participación en el mercado, sí se refleja en el costo final de los bienes y servicios que se ofrezcan (cfr. Butter y Mosch, 2003).

Un fundamento adicional para la legalización de propuestas de armonización legislativa es la reducción del riesgo legal. De conformidad con Rodríguez-Fernández (2009), "en un contexto globalizado [donde] existen múltiples ordenamientos que pueden llegar a regir una transacción internacional, los agentes que hacen parte de dicha relación deberán estar pendientes de las diferentes reglas que pueden aplicarse a su operación" (p. 245). Lo dispuesto genera aumento en el riesgo legal por la legalización del respectivo acto jurídico, entendiendo por riesgo legal, "la incertidumbre acerca del sistema normativo que regirá las relaciones nacidas como producto de una transacción de comercio internacional” (p. 245).

En este orden de ideas, la incertidumbre que, para los entes contratantes, genera no evidenciar un conocimiento claro sobre el marco normativo aplicable a una transacción internacional es una de las principales razones que desestimulan la inversión extranjera. Por ello, la eliminación del riesgo legal, a través de la consolidación de propuestas de armonización legislativa, traería consigo un sistema jurídico en el que no habría lugar a dudas a la hora de identificar o interpretar el texto normativo. En últimas, esto permitiría que las partes pudieran conocer con certeza el resultado de una futura disputa (cfr. Blanco-Alvarado, 2014).

Para finalizar, como el último fundamento para consolidar propuestas de armonización legislativa en la CAN, lo circunscribimos a que dicho instrumento permite fortalecer los conocimientos y cualidades de los distintos protagonistas que intervienen en la temática objeto de armonización legislativa. La existencia de un instrumento de armonización legislativa permitiría a los citados 
protagonistas adquirir un conocimiento común y especializado, y abrirá la puerta para una continua intercomunicación. Dicha retroalimentación mejora el entendimiento del texto armonizador y optimiza la prestación de bienes y servicios dentro de la CAN, a pesar, incluso, de las falencias que pueda contener el instrumento armonizador (BlancoAlvarado, 2013).

\section{Conclusiones}

Los países que integran a la Comunidad Andina están comprometidos con la suscripción del Acuerdo de Cartagena de promover la armonización gradual de sus políticas económicas y sociales y aproximación de las legislaciones nacionales (Blanco-Alvarado, 2013).

La realidad jurídica contemporánea exige establecer instrumentos a través de los cuales se simplifique el panorama legislativo andino. Desde la citada perspectiva la armonización legislativa constituye instrumento jurídico capaz de simplificar el contexto normativo de los países miembros de la CAN.

Es importante considerar que el fin del proceso de integración andino, es el desarrollo de los países vinculados al proceso, por lo que resulta procedente afirmar que el proceso andino de integración no es más que la herramienta para que estos países puedan desarrollarse económica, política, social y jurídicamente, de manera más rápida, eficaz y eficiente. En este sentido, las propuestas de armonización legislativa resultan procedentes para lograr la anhelada integración y, a la vez, congruencia en los sistemas jurídicos de los Estados andinos.

La realidad contemporánea exige mejorar la calidad de los marcos normativos de los países miembros de la CAN. Para ello, resulta de importancia recontextualizar la legislación comunitaria existente, desde las competencias compartidas entre los Estados andinos y la CAN, a fin de lograr que sea más coherente y contextualizada frente a los efectos de la globalización.

La finalidad de los procesos de armonización legislativa en la CAN es la aproximación de los sistemas jurídicos de los países miembros, para reducir el riesgo legal, mejorar la calidad y coherencia de las normas que rigen el comercio internacional y, por último, fortalecer los conocimientos técnicos jurídicos de los distintos agentes que participan en una transacción internacional.

Atendiendo la cláusula general de competencia legislativa que ostenta el legislador en los países miembros de la CAN, es importante resaltar que la armonización legislativa no puede ser entendida como un obstáculo para el desarrollo creativo del legislador. Por el contrario, los instrumentos de armonización legislativa son el ambiente más propicio para implementar nuevas políticas, crear nuevas soluciones políticas, económicas, sociales y jurídicas en el espacio de la Subregión Andina.

La consolidación de propuestas de armonización legislativa en la CAN supone el compromiso de los países andinos de abandonar sus tradiciones jurídicas, en búsqueda de lograr la suscripción y promulgación de disposiciones normativas neutrales, que respondan a las necesidades de la población vinculada al proceso andino de integración.

El procedimiento de armonización legislativa tiene como consecuencia inevitable la modificación de la legislación de algunos o de todos los países que participan en el proceso armonizador. Lo anterior busca lograr afinidad entre los distintos ordenamientos jurídicos nacionales.

La armonización legislativa es el medio idóneo para lograr certeza en cuanto al régimen aplicable para la solución de los conflictos políticos, económicos, jurídicos y sociales, ya que a través del instrumento armonizador se obtiene claridad sobre los efectos de la normativa que debe aplicarse.

La herramienta jurídica de la armonización legislativa genera disposiciones normativas constituidas para satisfacer las necesidades de la población andina. Al mismo tiempo, es un mecanismo legislativo que permite solucionar las dificultades que suelen presentarse en el desarrollo de las competencias compartidas entre la CAN y los países miembros.

Antes de consolidar una propuesta de armonización legislativa, es necesario examinar la problemática que se busca que sea resuelta a través del proceso armonizador, a fin de establecer si verdaderamente amerita el desarrollo de un proceso de esta envergadura. De lo contrario, el instrumento 
armonizador no será utilizado y, en consecuencia, no producirá los efectos deseados.

Es evidente que, difícilmente, podremos compartir una idéntica regulación normativa dentro de los países que integran a la CAN. Sin embargo, sí es posible iniciar el procedimiento legislativo comunitario de acercar los sistemas jurídicos de los países andinos en las temáticas que sean de interés común.

\section{Referencias}

Aldana, J. M. B. (2013). La armonización del Derecho, concepto y críticas en cuanto a su implementación. Revista e-mercatoria, 12(2), 80-139.

Bar, C. (2002). From Principles to Codification: Prospects for European Private Law. Columbia Journal of European Law, 8(3). https://bit.ly/3yhvs2i

Barragán-Ronderos, D. B. (2016). La construcción de la mentalidad democrática como necesidad en el posconflicto. Via Inveniendi et Iudicandi, 11(1), 37-57. https:// doi.org/10.15332/s1909-0528.2016.0001.06

Blanco-Alvarado, C. (2013a). Aproximación a la noción de soberanía estatal en el marco del proceso andino de integración. Revista Republicana [en línea], 15. https:// bit.ly/3oi8SBK

Blanco-Alvarado, C. (2013b). Algunas propuestas frente a la crisis de legitimidad de la comunidad andina (CAN). Análisis Político, 26(78), 141-155.

Blanco-Alvarado, C (2014). La crisis de la Comunidad Andina. Revista de Derecho, 42, 1-32.

Blanco-Alvarado, C. (2017). Condiciones de cohesión entre la comunidad andina (can) y la descentralización territorial colombiana. Revista Republicana [en línea], 23. https://bit.ly/3ybCDsB

Blanco-Alvarado, C. (2015a). La conexión entre descentralización territorial colombiana e integración andina. Análisis Político, 28(84), 207-216. https://doi. org/10.15446/anpol.v28n84.54647

Blanco-Alvarado, C. (2015b). La influencia positiva de la CAN en la descentralización territorial colombiana. Opinión Jurídica, 14(27). https://bit.ly/3uR3ecs

Buenaventura, E. F. (2013). Globalización del derecho, fetichismo legal el velo de los Derechos Humanos. Verba Iuris, 30, 169-181. https://doi.org/10.18041/0121-3474/ verbaiuris.30.2154
Den Butter, F. A. y Mosch, R. H. J. (2003). Trade, Trust and Transaction Costs (ssRn Scholarly Paper ID 459501). Social Science Research Network. https://doi.org/10.2139/ ssrn. 459501

Calonje, J. y Palomares, N. (2015). Tratados de libre comercio Colombia-Asia: Cuestión preliminar y perfiles de negociación. Iusta, 43. https://doi.org/10.15332/s19000448.2015.0043.06

Cortés-Zambrano, S. P. C. (2013). La globalización económica y los derechos humanos. Via Inveniendi Et Iudicandi, 8(2), 138-149. https://doi.org/10.15332/ s1909-0528.2013.0002.06

Faíña, J. A. y Novo, I. (2005). Constitución y orden jurídico-político de la economía europea. ¿Qué y para qué? En C. Molina (Dir.). El diálogo entre los pueblos y las culturas en el marco de las relaciones eurolatinoamericanas. Las perspectivas de las entidades subestatales. El caso de Galicia (pp. 109-141). Dijusa.

Forero-Salcedo, J. R (2014). El valor superior de la Justicia en la Unión Europea. Especial referencia al Estado Constitucional Social y Democrático de Derecho Español. Verba Iuris, 31, 91-114. https://doi.org/10.18041/01213474/verbaiuris.31.59

Gallego-Marín, J. A. (2014). Paradoja y complejidad de los derechos humanos en la sociedad moderna. Sentido y comunicación. Iusta, 40. https://doi.org/10.15332/ s1900-0448.2014.0040.01

Gobiernos de Bolivia, Colombia, Ecuador, Perú y Venezuela (1969, 26 de mayo). Por el cual se acuerda la integración subregional andina, refrendado por la ALALC en la Resolución 179 del 9 VII 1969; denominado Acuerdo de Cartagena en memoria del Manifiesto de Cartagena de 1813 [Acuerdo de Cartagena]. http://idatd.cepal.org/ Normativas/CAn/Espanol/Acuerdo_de_Cartagena.pdf

Gobiernos de Bolivia, Colombia, Ecuador, Perú y Venezuela (1979). Tratado constitutivo del Parlamento Andino. http://www.sice.oas.org/Trade/Junac/Parl1979.pdf

Goldring, J. (1978). "Unification and Harmonisatton" of the Rules of Law. Federal Law Review, 9(3), 284-325. https://doi.org/10.1177/0067205X7800900302

Gopalan, S. (2003). Transitional Commercial Law: The Way Forward. American University International Law Review, 18(4), 803-849.

Humbarita, J. I. (2015). Derecho Constitucional Hispanoamericano frente a la realidad institucional, manifiesta divergencia. Iusta, 43. https://doi.org/10.15332/s19000448.2015.0043.03 
Keily, T. (2003). Harmonisation and the United Nations convention on contracts for the international sale of goods. Nordic Journal of Commercial Law, 1, 1-21.

Lerner, P. (2004). Sobre armonización, derecho comparado y la relación entre ambos. Boletín Mexicano de Derecho Comparado, 1(111). https://doi.org/10.22201/ iij.24484873e.2004.111.3807

Martínez, E. R. (2016). El pasaje del estado y el derecho a la postmodernidad. Via Inveniendi Et Iudicandi, 11(2), 1137. https://doi.org/10.15332/s1909-0528.2016.0002.01

McKendrick, E. (2006). Harmonisation of European Insurance Contract Law. En S. Vogenauer y S. Weatherill (Eds.), Harmonisation of European Contract Law. Implications for European Private Laws, Business and Legal Practice (pp. 5-28). Bloomsbury.

Momberg-Uribe, R. (2009). Análisis crítico del proceso de armonización del derecho contractual en la Unión Europea. Revista de Derecho (Valdivia), 22(1), 9-33. https://doi.org/10.4067/S0718-09502009000100001

Patarroyo, S. P., y Benavides, P. A. (2014). Rupturas significantes: Revisiones críticas en torno al Derecho. Via Inveniendi et Iudicandi, 9(1), 7-31. https://doi. org/10.15332/s1909-0528.2014.0001.01

Quiroz-Villalobos, M. (2014). Un acercamiento a las “oposiciones paradigmáticas" entre neoconstitucionalismo y positivismo jurídico. Iusta, 41. https://doi. org/10.15332/s1900-0448.2014.0041.03

Ramírez, E. A. G. (2013). Persona y realización efectiva de derechos. Iusta, 38. https://doi.org/10.15332/s19000448.2013.0038.05

Rodríguez, M. S. (2007). Armonización legislativa en materia de salvataje de salvataje de empresas en el Mercosur: ¿una quimera o una necesidad? Universidad de Buenos Aires.

Rodríguez, M. S. (2016). Bases de armonización legislativa en materia de salvataje de empresas en el Mercosur. Revista Electrónica Instituto de Investigaciones Jurídicas y Sociales A. L. Gioja, 0(2), 91-125.
Rodríguez-Cely, A. M. (2014). Indicadores de constitucionalidad de las políticas públicas: Enfoque de gestión de derechos. Via Inveniendi et Iudicandi, 9(2), 135-175. https://doi.org/10.15332/s1909-0528.2014.0002.06

Rodríguez-Fernández, M. (2009). Introducción al derecho comercial internacional. Universidad Externado de Colombia.

Roumeen, I y Reshef, A. (2006). Trade and Harmonization: If Your Institutions are Good, Does it Matter If They are Different? (SSRN Scholarly Paper, No. 917478). Social Science Research Network. https://papers.ssrn.com/ abstract $=917478$

Sacco, R. (1989). Introduzione al diritto comparato $\left(3 .^{\mathrm{a}}\right)$. UTET Giuridica.

Saidiza, H y Carvajal, J. (2016). Crisis del Estado de derecho en Colombia: Un análisis desde la perspectiva de la legislación penal. Iusta, 44, Article 44. https://doi. org/10.15332/s1900-0448.2016.0044.01

Sieg, E. (2010). Globalization and Harmonization of International Trade Law. En Globalization and International Trade Law. Edward Elgar Publishing. https://doi. org/10.4337/9781849805216

Stephan, P. B. (1999). The Futility of Unification and Harmonization in International Commercial Law (SSRN Scholarly Paper, No. 169209). Social Science Research Network. https://doi.org/10.2139/ssrn.169209

Viver, C. V. (1996). Tècnica legislativa: Estat de la qüestió i balanç (provisional) d'una dècada. Revista Catalana de Dret Públic, 0(21). http://revistes.eapc.gencat.cat/ index.php/rcdp/article/view/1936

Wagner, G. (2007). Transaction Cost, Choice of Law and Uniform Contract Law. Congress to Celebrate the Fortieth Annual Session of Uncitral. Modern Law for Global Commerce, Viena.

Zweigert, K. (1998). An Introduction to Comparative Law (T. Weird, Trad.). Oxford University Press. 